\title{
Change detection of bare areas in the Xolobeni region, South Africa using Landsat NDVI.
}

\author{
Rebekah Gereldene Singh ${ }^{1}$, Jeanine Engelbrecht ${ }^{2}$, Jaco Kemp ${ }^{3}$ \\ ${ }^{1}$ Council for Geoscience, South Africa, rgrow@geoscience.org.za \\ ${ }^{2}$ Council for Scientific and Industrial Research, South Africa \\ ${ }^{3}$ Stellenbosch University, South Africa
}

DOI: http://dx.doi.org/10.4314/sajg.v4i2.6

\begin{abstract}
Identification and protection of areas that are vulnerable to erosion is essential for the conservation of the sensitive wetlands and estuarine ecosystems along the Xolobeni coastal strip. The forecasting of these erosion susceptible areas requires an understanding of the interrelationships of the critical factors that have influenced erosion potential over time. Vegetation and bare areas are some of the contributing factors that have influenced erosion at Xolobeni. This study used remote sensing as a tool to provide some information on the inter-relationship between vegetated classes and bare areas. Normalised Difference Vegetation Index (NDVI) data derived from multi-temporal Landsat 5 imagery has formed the baseline information for this study. A density slicing approach was adopted to classify the region into four vegetation structure classes of predominant land cover types. Post classification change detection data has provided an understanding of the relative susceptibility of the different vegetated classes to being degraded to bare areas. The results suggest that poorly vegetated regions were most susceptible to further degradation and an elevated susceptibility to erosion. On the other hand, moderately and densely vegetated regions were less susceptible to land degradation. The information can be used to identify measures to mitigate the effects of land degradation in vulnerable areas.
\end{abstract}

\section{Introduction}

Soil erosion has been recognised as a major environmental issue in South Africa (Meadows, 2003, Le Roux et al., 2008), which also poses social and economic threats (Beringer, 2006). Erosion affects various regions in South Africa, with some areas being more affected than others. One such area is the Xolobeni coastal strip along the Eastern Cape Wild Coast where communal seasonal crop lands have been severely degraded by water and wind erosion (Singh et al., 2014). On the Neogene coastal barrier dune ridge at Xolobeni, intense leaching and pedogenic bleaching of the surficial soil horizons developed in rubified dune sands have formed grey sandy soils that are being actively eroded. The high rate of uncontrolled soil erosion poses a significant threat to the local environment and cultural activities and has led to localised desertification. 
Conservation planning to protect the sensitive wetlands and estuaries must identify areas that are most susceptible to erosion, thereby facilitating mitigation and prevention of further degradation within the Xolobeni region. The identification of such areas requires an understanding of the interrelationships associated with key wind and water erosion contributing factors. Analysis of airborne data along this coastal strip has highlighted that erosion often initiates in patches of disturbed vegetation or bare ground. Conversely, patches of dense vegetation thicket are able to slow the rates of lateral spread of large parabolic 'blowout' erosion landforms (Singh et al., 2014). According to Kemp (2010), the application of remote sensing in erosion research within South Africa has focussed on mapping bare soil and characterisation of vegetation as precursors of erosion potential.

This study has used remote sensing as a tool to map the broad vegetation structure categories of the predominant land cover types and provide insight into the inter-relationship of change patterns between the vegetated classes and bare areas that have influenced erosion potential over time. The relatively simple Normalised Difference Vegetation Index (NDVI) has been identified as a proxy that can aid mapping of land degradation patterns (Waswa, 2012). Therefore, NDVI time series data was adopted in this study to assess and understand past vegetation structure change conditions that may have contributed to the widespread land degradation existing at Xolobeni. NDVI values have been used to classify the Xolobeni region into four vegetation structure classes that relate to the major land cover types. These classes include bare ground, degraded grassland/poorly vegetated land, moderately vegetated land and densely vegetated land. Descriptions of the vegetation structure classes for the main land cover types have been adapted from Thompson (1996) and Ngcofe (2008) (Table 1). This paper describes the NDVI classification and interprets the results of the post classification change detection for the period 1997 to 2010 with a focus on bare areas.

Table 1. Descriptions of the broad vegetation structure classes of the predominant land cover types, modified after Thompson (1996) and Ngcofe (2008)

\begin{tabular}{|l|l|}
\hline Class name & Class descriptions \\
\hline $\begin{array}{l}\text { Densely vegetated } \\
\text { (Thicket and wetlands) }\end{array}$ & Areas of dense interlaced vegetation, associated with 70\% cover. \\
\hline $\begin{array}{l}\text { Moderately vegetated } \\
\text { (Grassland) }\end{array}$ & Areas associated with less than 10\% tree and/or shrub canopy cover. \\
\hline $\begin{array}{l}\text { Poorly vegetated } \\
\text { (Degraded grassland) }\end{array}$ & $\begin{array}{l}\text { Areas of very low vegetation cover, often associated with } \\
\text { anthropogenic activity }\end{array}$ \\
\hline $\begin{array}{l}\text { Bare areas } \\
\text { (Bare ground) }\end{array}$ & $\begin{array}{l}\text { Exposed soil or rock surfaces, associated with anthropogenic activity } \\
\text { and/or natural causes. }\end{array}$ \\
\hline
\end{tabular}

\section{Study area and description}

The Xolobeni coastal zone is located in the Eastern Cape Province between the Mnyameni River in the north and the Mtentu River in the south (Figure 1). The study area has been delineated as a 3 $\mathrm{km}$ wide strip inland from the Indian Ocean shoreline and is associated with irregular topography, 
Neogene to Quaternary weathered rubified sands of older dunes and a sub-tropical climate. This region is known to have widespread erosion features (Singh et al., 2014) and is confined to the coastal zone that falls within the T60D Quaternary sub-catchment (Midgley et al., 1994). The study area is drained by the Mnyameni, Mtolane, Kwanyana, Sikombe and Mtentu Rivers as well as their tributaries. Some rivers, estuaries and interdune wetlands in this area have been severely affected by the sedimentation which may be attributed to the active erosion occurring within the study area.

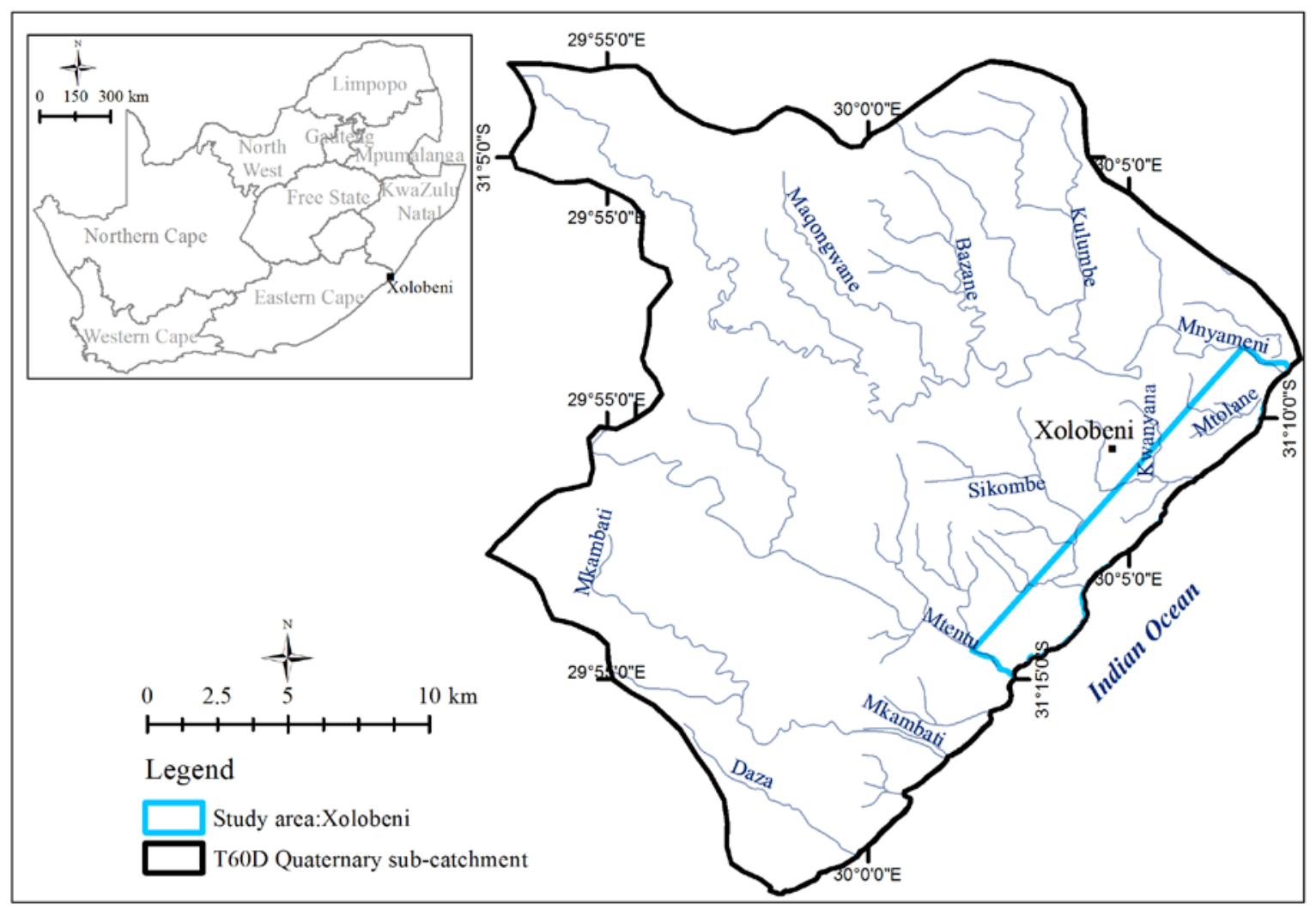

Figure 1. Locality map showing the Xolobeni study area

\section{Materials and methods}

The analysis was performed using Landsat 5 data, captured at the end of the wet season (April) for the years 1997, 2004 and 2010. End of wet season imagery were selected in order to ensure higher contrast between bare zones and vegetated areas. The Landsat data were acquired from South African National Space Agency (SANSA) and a standard terrain correction (Level 1T) had been applied to all scenes. Pre-processing involved the calibration of Landsat bands 1 to 5 and 7 by converting digital numbers to top of atmosphere reflectance, thereby reducing scene-to-scene variability (Chander et al., 2009). After calibration, the data were transformed to single band NDVI images using Equation 1 as follows: 
Near zero and negative NDVI values indicate non-vegetation classes whilst positive values represent different types of vegetation classes (Yacouba et al., 2009). Agone and Bhamare (2012) have associated NDVI values of 0.00 - 0.20 with bare areas. Masks defining the Xolobeni study region were created and applied to the time series of NDVI images. The 2010 NDVI data was used as the pilot dataset in the determination of threshold values (density slices) for classifying the Xolobeni region into bare areas, poorly vegetated, moderately vegetated and densely vegetated classes. The threshold values determined for the 2010 NDVI dataset were subsequently applied to the 2004 and 1997 images. According to Yang and Mueller (2007) the accuracy of postclassification change detection is dependent on the accuracy of the input classification data. Since the accuracy of classified data was critical to the quality of the post classification change detection results, confusion matrices were determined for all three classified images. Available aerial photography and field knowledge were used for the selection of ground truth data for the accuracy assessments.

\section{Results}

\subsection{NDVI classification}

The classification of NDVI data relied on the threshold values determined for classifying the data as bare soil, poorly vegetated, moderately vegetated and densely vegetated classes respectively. Areas exhibiting NDVI values of less than 0.0396 were associated with zones of water and/or masked pixels. NDVI values between 0.0396 and 0.2813 were found to represent bare ground. Poorly vegetated areas were characterised by NDVI values of 0.2813 to 0.4424 , whilst NDVI values of 0.4424 to 0.6036 and NDVI values greater than 0.6036 were used to classify moderately vegetated and densely vegetated zones respectively.

The results of the classification are presented in Figures 2 for the 1997, 2004 and 2010 scenes. On the classified scenes, bare ground is shown in yellow, cyan represents poorly vegetated zones, moderately vegetated areas are displayed in light green, densely vegetated regions appear dark green and black indicates zones of water and/or masked pixels. 


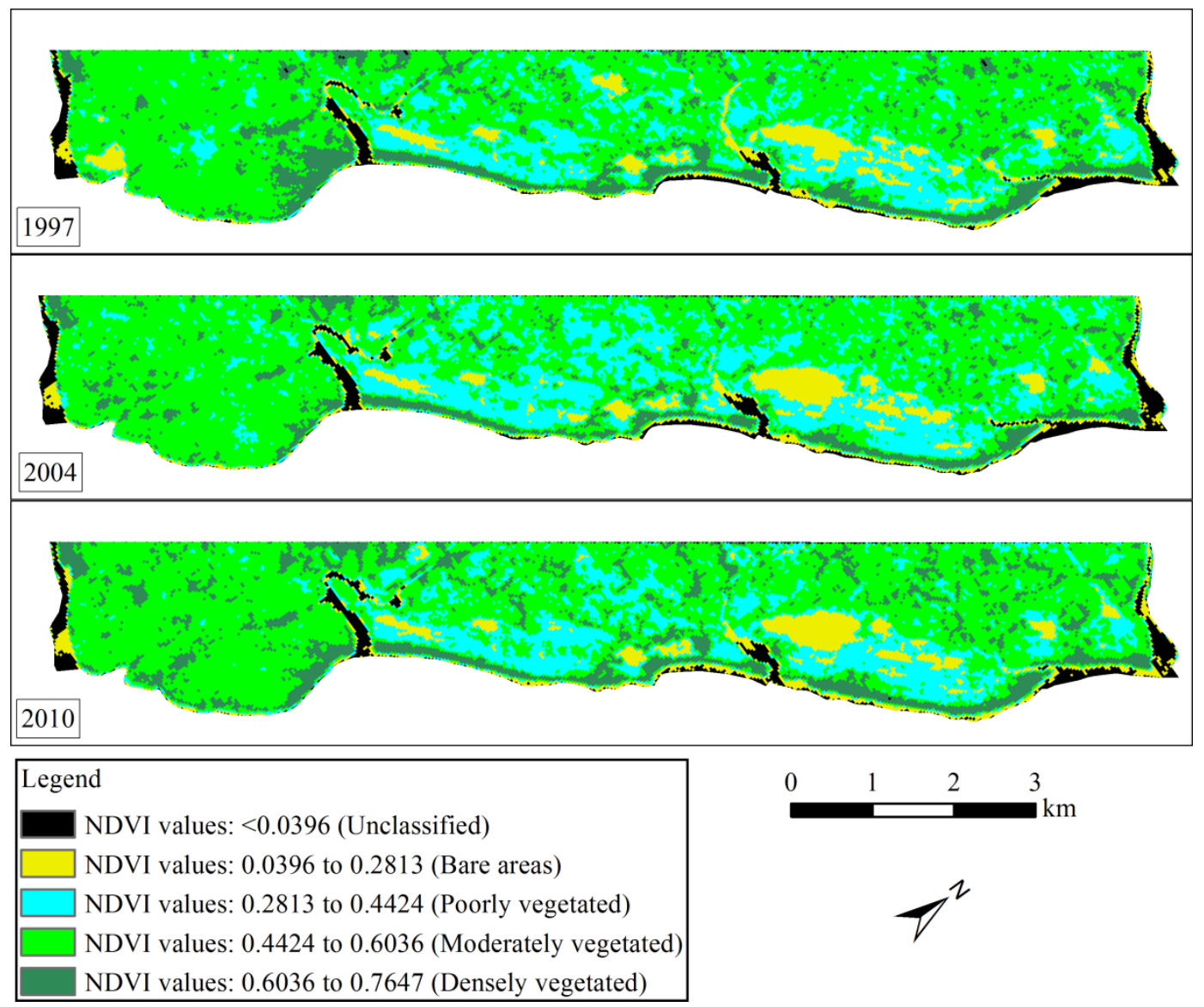

Figure 2. The 1997, 2004 and 2010 NDVI classification data

\subsection{Classification accuracy}

Since the accuracy of post-classification change detection is dependent on the accuracy of the classified data used as input, confusion matrices for the 1997, 2004 and 2010 classifications were calculated. The derived confusion matrices evaluated the accuracy of the classification results through the comparison of the classification results with ground truth information selected from selected aerial photography. The mosaicked, georeferenced 1995, 2003 and 2009 aerial photography were used for the visual, pixel-based selection of the regions of interest that formed the basis of the accuracy assessments since these images respectively provided the closest temporal correlation.

The NDVI classifications for all three years achieved overall accuracies of greater than $81.00 \%$ and Kappa coefficients of above 0.74 (Figures 3A-C). For the 1997 image, 90.12\% of bare areas were correctly classified, with $9.38 \%$ and $0.49 \%$ being confused with poorly and moderately vegetated areas, respectively. Accuracy assessments of the 2004 and 2010 images show superior results for bare areas, with accuracies above 94.69\% being achieved and less that 6\% being erroneously classed as poorly vegetated areas. The confusion matrices show that the poorly vegetated class has been mapped with lowest precision, attaining a maximum accuracy of $78.57 \%$ 
in 2004. Although the poorly vegetated class experiences confusion between with all other classes (for all dates), most confusion is evident with the moderately vegetated areas. The 1997 and 2010 accuracy results show a relatively high confusion between poorly and moderately vegetated classes; more than $27.36 \%$ of the poorly vegetated class was incorrectly classified as moderately vegetated in 2010. In 1997, 2004 and 2010 moderately vegetated areas achieved accuracies of 83.38\%, 77.30\% and 83.67\%, respectively. Densely vegetated areas generally achieved higher accuracies compared to the other two vegetated classes, with accuracies in excess of $88.65 \%$. The NDVI thresholding technique achieved satisfactory overall accuracies and these classifications were subsequently used for the post-classification change detection analysis.

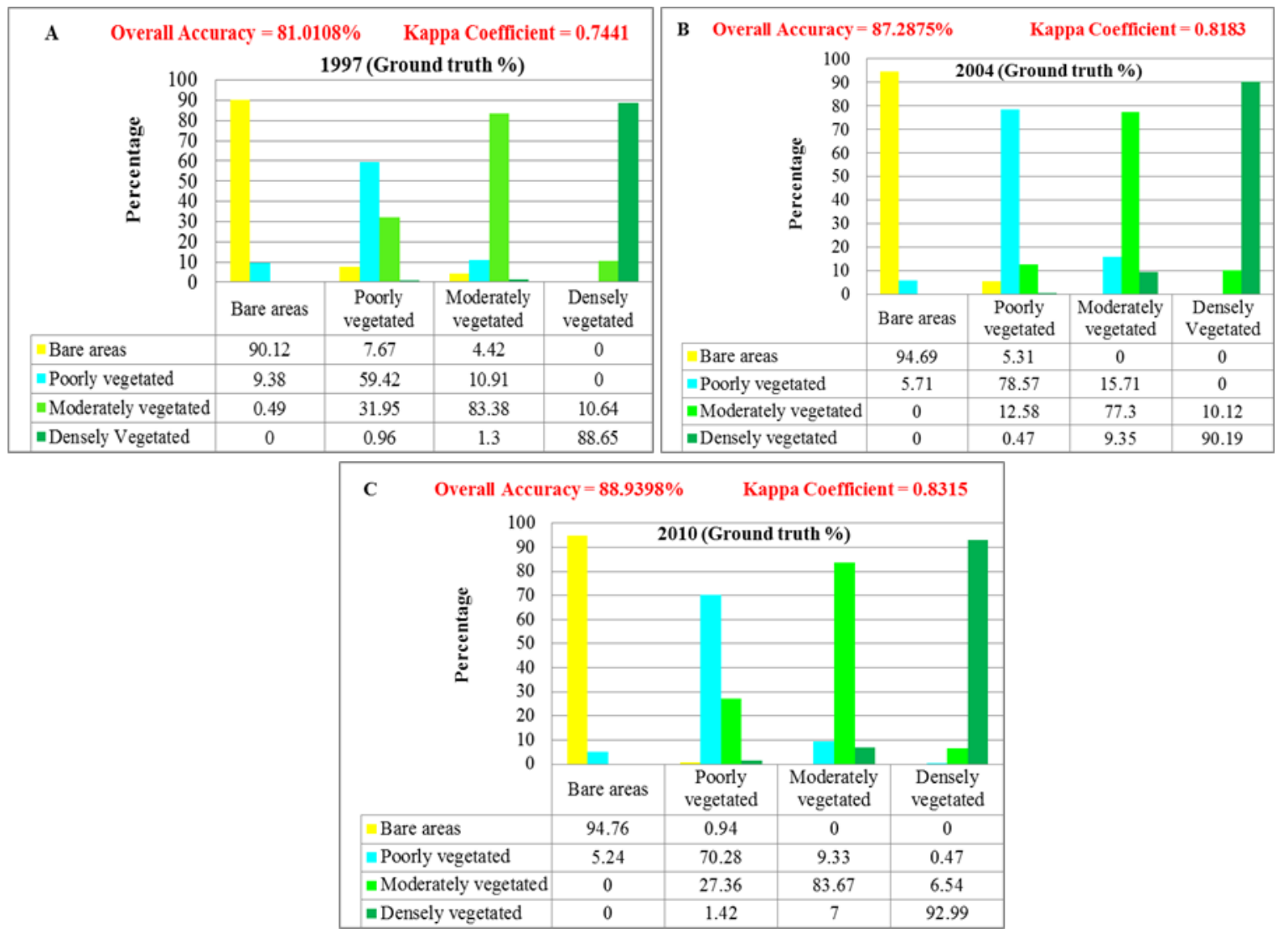

Figure 3. Graphs showing the accuracy of the (A) 1997, (B) 2004 and (C) 2010 classifications expressed as a percentage of the total ground truth pixels per vegetation structure class

\subsection{Post-classification change detection}

To gain knowledge on the inter-relationship of change patterns between the vegetated classes and bare areas that have influenced erosion development over time, post classification change detection was performed. Change detection analyses the changes in individual vegetated classes as well as the exchanges that occur between them over time. Change detection statistics were derived for the periods 1997 - 2004, 2004 - 2010 and 1997 - 2010. The number of pixels that were classified as each of the four classes are summarised in Table 2. The percentage change in the area associated with each class is presented graphically in Figure 4. It is evident that the bare soil class is 
associated with a small change in total area with a 0.41\% decrease in size between 1997 and 2004 and a 3.19\% increase in area between 2004 and 2010. Similarly, the moderately vegetated class exhibits a 4.00\% decrease in area between 1997 and 2004 and a 1.88\% increase in area between 2004 and 2010. In contrast, significant changes in the areas associated with the poorly vegetated class and the densely vegetated class are observed. The poorly vegetated class exhibits a $26.71 \%$ increase in area between 1997 and 2004 and a 25.25\% decrease in area between 2004 and 2010 while the densely vegetated class exhibits a $27.22 \%$ decrease and $66.32 \%$ increase from 1997 to 2004 and 2004 to 2010 respectively.

Table 2. The number of pixels classified from 1997 to 2010, of the vegetation structure classes

\begin{tabular}{|l|l|l|l|}
\cline { 2 - 4 } \multicolumn{1}{c|}{} & $\mathbf{1 9 9 7}$ & $\mathbf{2 0 0 4}$ & $\mathbf{2 0 1 0}$ \\
\hline Bare areas & 1953 & 1945 & 2007 \\
\hline Poorly vegetated & 5297 & 6712 & 5017 \\
\hline Moderately vegetated & 15599 & 14967 & 15249 \\
\hline Densely vegetated & 3170 & 2307 & 3837 \\
\hline
\end{tabular}

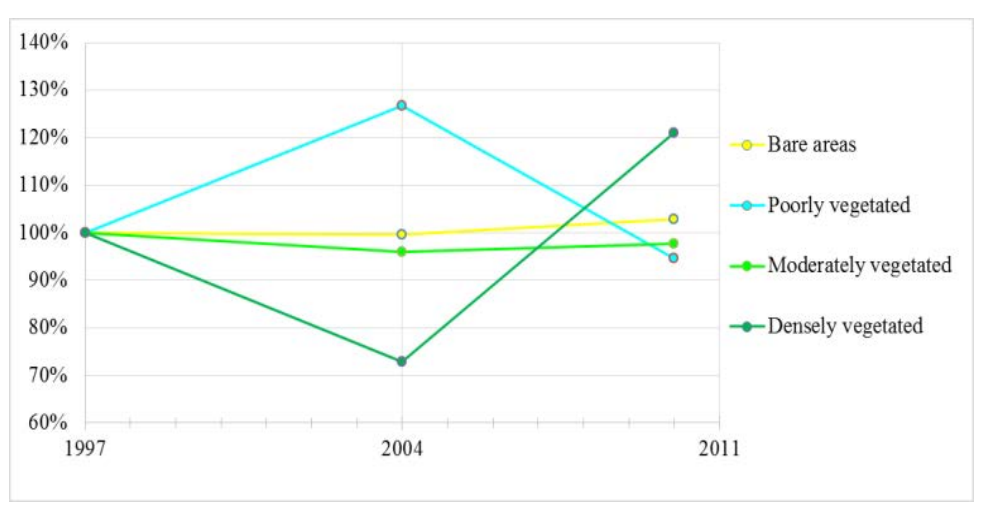

Figure 4. Class change expressed as percentage relative to 1997 for the period 1997 to 2010

The class exchanges data for the 1997 - 2004, 2004 - 2010 and 1997 - 2010 periods have provided insight on inter-class relationships associated with bare areas and the vegetated classes. The percentage change from one class to another is shown Figure 5A-C for the period between 1997 and 2004, 2004 and 2010 as well as between 1997 and 2010 respectively. The results reveal that the bare areas have been transformed predominantly to the poorly vegetated class although changes to moderate and dense vegetation are also observed in the period 1997-2010. 18.08\% of the bare areas in 1997 transformed to poorly vegetated pixels while 9.11\% of bare areas transformed to the moderately vegetated class in 2010. Furthermore, 5.38\% of bare area pixels remained unclassified in the 2010 scene, possibly due to the expansion of open water features and $0.46 \%$ of bare areas were converted to the densely vegetated class (Figure 5C). However, there has been a simultaneous increase in bare area pixels from the vegetated classes in other areas. Vegetation structure class exchange data for the periods 1997 - 2004, 2004 - 2010 and 1997 - 2010 have highlighted that the largest change to/from bare areas is associated with the poorly vegetated class (Figure 5A-C). The three change detection results indicate that $8.44 \%$, 3.05\% and $7.55 \%$ of poorly 
vegetated pixels transformed to bare areas in the periods 1997 - 2004, $2004-2010$ and 1997 2010 respectively. Over time there has been some change from moderately vegetated pixels to bare areas, a maximum of $0.67 \%$ change was evident in the period 1997 - 2010 (Figure 5C).

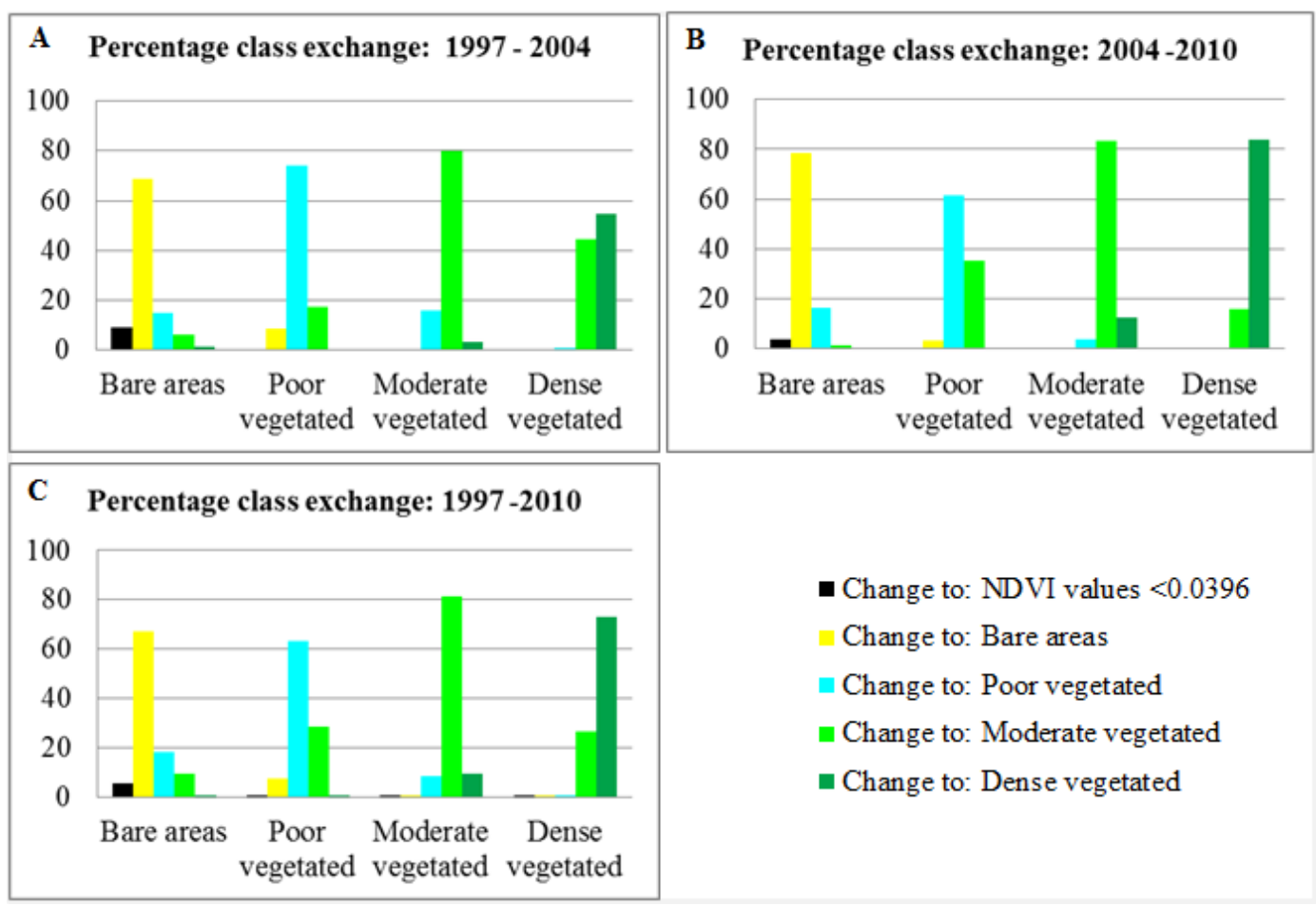

Figure 5. Exchanges between classes for the period (A) 1997 - 2004, (B) 2004 - 2010 and (C) 1997 $-2010$

The post-classification change detection process has also importantly allowed for the creation of change detection mask images pertaining to the bare areas, poorly vegetated, moderately vegetated and densely vegetated classes. Figure 6 shows the change detection mask images that were derived for the 1997 and 2010 NDVI classified data. The results reveal that relatively more transformation to bare areas from poorly vegetated areas has occurred between the Mnyameni and Sikombe Rivers, with significant exchange being evident between the Mtolane and Kwanyana Rivers (Figure 6). Some significant change to bare areas from the moderately vegetated class has been observed in two locations. This occurs in the area between the Mtolane and Kwanyana Rivers as well as immediately south of the Sikombe River. The transformation of poorly vegetated and moderately vegetated areas into bare areas indicates an increase in degraded land. 


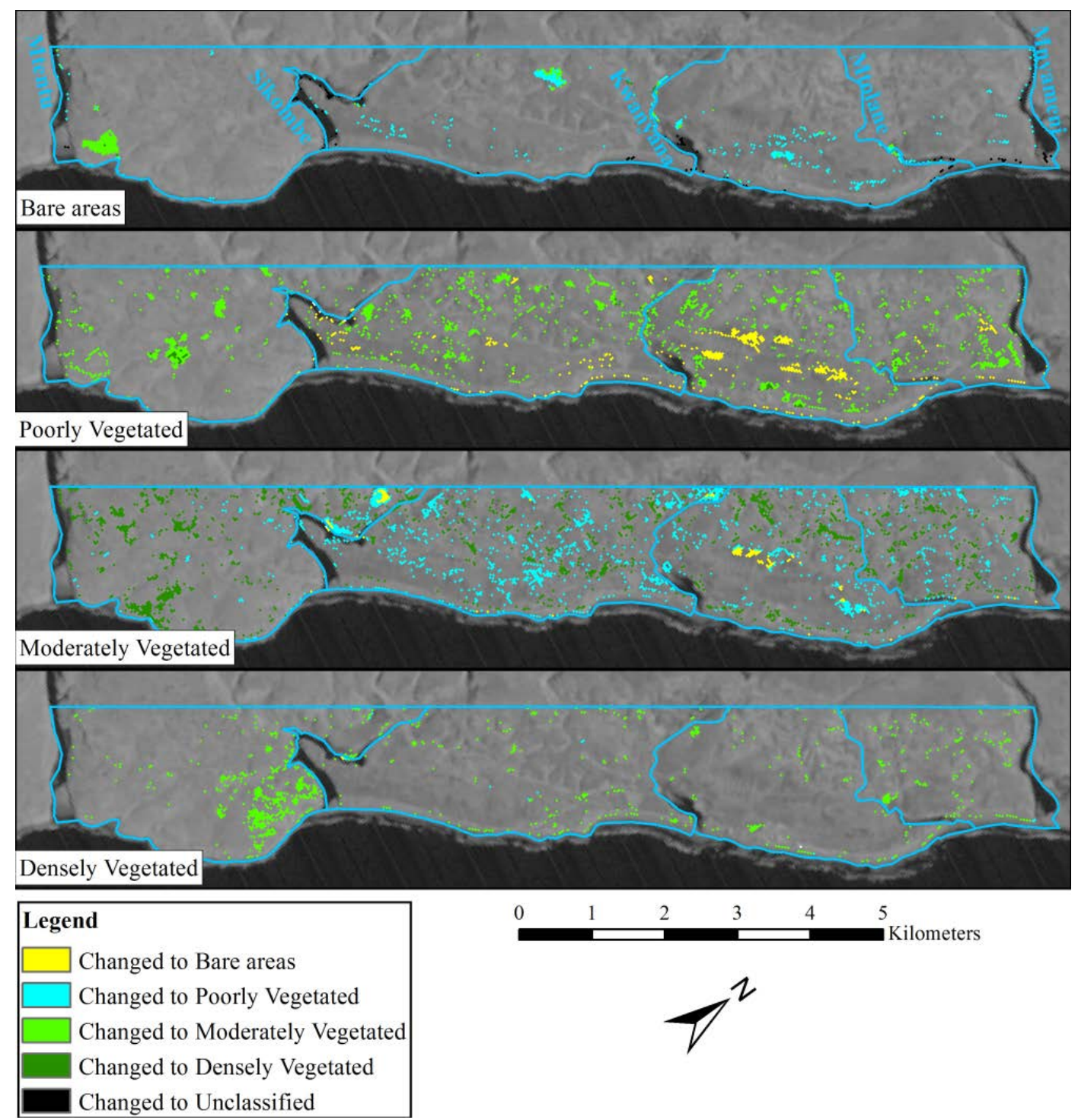

Figure 6. A compilation of the four change detection mask images obtained through the comparison of the 1997 and 2010 NDVI classified data

\section{Discussion, conclusion and recommendation}

The NDVI-density slicing technique has shown promise for the detection of bare areas in rural Xolobeni. Apart from yielding overall satisfactory accuracies, this technique offered a quick and easy method to detect bare areas along the coastal strip. Post classification change detection highlighted the relative susceptibility of each of the vegetated classes to being degraded to bare areas. Based on the change detection statistics it can be deduced that poorly vegetated areas are most susceptible to bare area development whilst moderately and densely vegetated zones are less vulnerable. This deduction complements the observation of Singh et al. (2014) that the presence of more dense peripheral vegetation has supressed lateral spread of eroded landforms along the Xolobeni coastal strip. The change detection analysis has revealed that the most significant change to bare areas has occurred between the Mtolane and Kwanyana Rivers. The results confirm the observation by Singh et al. (2014) that suggested that accelerated erosion was associated with this 
location. Furthermore, the erosion features were identified to have been initiated by anthropogenic activities where bare patches in communal farmlands or along access tracks were associated with the accelerated degradation over time.

In contrast to the region north east of the Kwanyana River, the area between the Kwanyana and Sikombe Rivers as well as between the Sikombe and Mtentu Rivers has been less adversely affected by widespread bare area development over time. In fact, an increase in dense vegetation is observed between the Sikombe and Mtentu Rivers although some changes from dense vegetation to moderate vegetation are also observed (Figure 6). The observed increase in vegetation supports the observation by Singh et al. (2014) that the presence of peripheral vegetation deters the development of bare areas and are, in cases, associated with the encroachment of vegetation into areas previously associated with bare areas. The presence of vegetation acts as a wind barrier, effectively preventing the spread of blowout erosion features as observed by Singh et al. (2014). The presence of vegetation can, in cases, even reverse the effects of erosion as was observed between the Sikombe and Mtentu Rivers where bare areas in 1997 changed to become moderately vegetated by 2010. The results suggest that the development of new erosion features can be mitigated by minimising bare patches along access tracks and within communal farmlands. Furthermore, to curb the growth of already established erosion features, peripheral vegetation barriers can be established to prevent further bare area development.

\section{Acknowledgements}

The authors would like to thank the Council for Geoscience and Department of Science and Technology for co-funding the research project. Gratitude is given to the South African National Space Agency (SANSA) and National Geo-spatial Information (NGI) for respectively providing the Landsat data and aerial photography used in the study. A very special thank you to Chiedza Musekiwa and Greg Botha for their expert guidance and advice.

\section{References}

Agone, V \& Bhamare, SM 2012, ' Change detection of vegetation cover using remote sensing and GIS', Journal Of Research And Development, vol.2, no.4, pp.1-11.

Beringer, G, 2006, The efficiency of some structures to prevent soil erosion - A case study in Mabula private game reserve. MSc dissertation, University of Johannesburg. 69pp.

Chander, G, Markham BL \& Helder DL 2009, 'Summary of Current Radiometric Calibration Coefficients for Landsat MSS, TM, ETM+ and EO-1 ALI Sensors’, Remote Sensing of Environment, vol.113, pp.893903.

Kemp, JN, 2010, The application of multi-source remote sensing for sediment transport mapping in an intertropical context (La Réunion Island and South Africa). PhD thesis, University of La Réunion: 226pp.

Le Roux, JJ, Morgenthal, TL, Malherbe, J, Sumner, PD \& Pretorius DJ 2008, 'Water erosion prediction at a national scale for South Africa', Water SA, vol.3, no.4 (3), pp.305-314. 
Meadows, MM 2003, 'Soil erosion in the Swartland, Western Cape Province, South Africa: implications of past and present policy and practice’, Environmental Science and Policy, vol.6, pp. 17-28.

Midgley, DC, Pitman, VW \& Middleton, BJ., 1994. Surface water resources of South Africa 1990, Book of Maps, vol V, WRC Report No. 298/5.2/94, Water Research Commission.”

Ngcofe, LDS, 2008, Assessment and monitoring of land degradation using remote sensing and geographic information systems (GIS): A case study of Qoqodala within the Wit-Kei catchment in the Eastern Cape, South Africa' MSc Thesis, Rhodes University.

Singh, RG, Engelbrecht, J, Botha, JN \& Kemp, J, (2014), 'Monitoring soil erosion features using a time series of airborne remote sensing data: A case study Wild Coast, South Africa', Proceeding of the 10th international conference of the African Association of Remote Sensing of the Environment (AARSE), Johannesburg.

Thompson, M 1996. 'A standard land cover classification for remote sensing applications in South Africa', South African Journal of Science, vol.92, pp.34-42.

Waswa, BS, 2012. 'Assessment of land degradation patterns in western Kenya:Implications for restoration and rehabilitation', PhD Dissertation. University of Bonn. 220p.

Yacouba, D, Guangdao, H \& Xingping, W 2009. 'Assessment of land use cover changes using NDVI and DEM in Puer and Simao counties, Yunnan Province, China’, World Rural Observations, vol.6, no.2, pp.1-11.

Yang, Z \& Mueller, R, 2007, 'Spatial-spectral cross-correlation for change detection-a case study for citrus coverage change detection’, ASPRS 2007 Annual Conference, Tampa, Florida, 11pp. 